\title{
Optimal Cost Minimization Strategy for Fuel Cell Hybrid Electric Vehicles Based on Decision Making Framework
}

\author{
Huan Li, Yang Zhou, Hamid Gualous, Member, IEEE, Hicham Chaoui, Senior Member, IEEE, Loïc Boulon, Senior \\ Member, IEEE
}

\begin{abstract}
The low economy of fuel cell hybrid electric vehicles is a big challenge to their wide usage. A road, health, and price-conscious optimal cost minimization strategy based on decision making framework was developed to decrease their overall cost. First, an online applicable cost minimization strategy was developed to minimize the overall operating costs of vehicles including the hydrogen cost and degradation costs of fuel cell and battery. Second, a decision making framework composed of the driving pattern recognition-enabled, prognostics-enabled, and price prediction-enabled decision makings, for the first time, was built to recognize the driving pattern, estimate health states of power sources and project future prices of hydrogen and power sources. Based on these estimations, optimal equivalent cost factors were updated to reach optimal results on the overall cost and charge sustaining of battery. The effects of driving cycles, degradation states, and pricing scenarios were analyzed.
\end{abstract}

Index Terms-Energy management, fuel cell hybrid electric vehicle, decision making, prognostics, driving pattern recognition, price evolution.

\section{INTRODUCTION}

\section{A. Motivation and challenges}

Due to the increasing severeness of air pollution and global warming, governments and international agencies have put forward many policies and taken many methods to reduce the effects on climate change. In the aspect of transportation, fuel cell hybrid electric vehicles (FCHEVs) take fuel cells and energy storage sources (ESSs) (battery in this paper) as the power sources and have many advantages like zero pollution, high efficiency, satisfied driving range, short refueling time, and not relying on fossil, which are thought a potential solution to the energy crisis and environment pollution [1]. The hybrid configurations of FCHEVs go with an energy management problem. Therefore, an energy management strategy (EMS) is needed for FCHEVs to control the distribution of power demand among different power sources. Compared to other electric vehicles and internal combustion engine vehicles, FCHEVs are lack of competition on overall cost due to the high cost and low lifetime of fuel cell and batteries [2]. Therefore, in

H. Li and H. Gualous are with the NORMANDIE UNIV, UNICAEN, LUSAC, Cherbourg, France (e-mail: huan.li@unicaen.fr; hamid.gualous@unicaen.fr).

Y. Zhou is with the FEMTO-ST (UMR CNRS 6174), FCLAB (FR CNRS 3539), Univ. Bourgogne Franche-Comté, UTBM (e-mail: yang.zhou@utbm.fr).

H. Chaoui is with the Intelligent Robotic and Energy Systems Research Group, Department of Electronics, Carleton University, Ottawa, ON K1S 5B6, Canada (e-mail: Hicham.Chaoui@carleton.ca ).

L. Boulon is with the Hydrogen Research Institute, Université du Québec à Trois-Rivières, QC G8Z 4M3, Canada (e-mail: loic.boulon@uqtr.ca). this paper, an optimal cost minimization strategy (OCMS) is developed to minimize the operating cost and improve the economy of FCHEVs.

\section{B. Literature review}

Studies on EMSs can be divided into the rule-based strategy (RBS) and optimization-based strategy (OBS) [3]. The heuristic rules are the core of the RBS. These rules can be expressed as the deterministic rules in deterministic rule-based strategies or fuzzy rules in fuzzy rule-based strategies. Based on these rules, the on/off of fuel cell, operating models of ESSs, and corresponding power of power sources are determined to make sure the normal operation of the vehicle. Load following strategy, operating mode control strategy and fuzzy logic control are typical RBSs. The RBSs can be easily designed by engineers based on their experience. The real-time implication of these RBSs is also simple and their resilience on different driving patterns is strong. But optimal results for the designed objectives of EMSs are hardly reached.

In order to overcome the deficiency of the RBS, OBS is designed to optimize the operation of vehicles and achieve the optimal objectives. The general configuration of OBS includes one or more optimal objectives and certain constraints such as limiting the state of charge (SOC) of ESSs and power ranges of power sources. Based on the optimization horizons, OBS can be divided into the global OBS taking the whole driving cycle as optimization horizons and local OBS on the instantaneous sampling time. Dynamical programming (DP), genetic algorithm (GA) and particle swarm optimization are widely used algorithms to solve global optimization problems to achieve optimal objectives [4, 5]. Equivalent consumption minimization strategy, Pontryagin's minimum principle (PMP) and model predictive control (MPC) are typical local OBSs [6, 7].

Many studies on EMSs for FCHEVs only focus on the minimization of hydrogen consumption or equivalent hydrogen consumption from ESSs without sufficiently considering the degradation of fuel cell and battery. A small number of studies try to make a tradeoff between battery degradation and hydrogen consumption. For example, in [8] and [9] discrete dynamic programming and convex optimization are respectively used to optimize the costs of battery degradation and hydrogen consumption. But the fuel cell degradation is not considered into the optimal objectives of these studies. In [10], minimizing the hydrogen and fuel cell lifetime costs as the objective function is solved through stochastic dynamic programming (SDP). Three representative EMSs: DP, PMP, and MPC in [11] are developed to minimize hydrogen consumption and fuel cell durability. In [12] and [13], the fuel cell models are identified online to find the variation of fuel cell 
system performances and to operate the fuel cell in the best efficiency and power operating points through PMP. Battery degradation is not considered in the above researches. The deficiency for the above researches on the minimizing oval cost of FCHEVs can be concluded as not considering all power sources degradation.

Fuzzy logic control optimized by GA in [14], MPC based sequential quadratic programming in [15] and DP in $[16,17]$ consider all hydrogen cost and degradation costs of fuel cell and battery. But empirical degradation models of fuel cell and battery used to calculate their degradation costs are not precise, which cannot describe the dynamical degradation rates of power sources under the dynamical conditions of vehicles like the changeable external environment condition, temperature, and operating conditions. The lifetime costs calculated based on the unprecise degradation rates bring a big challenge to the reliability of their developed EMSs. The deficiency for these researches can be defined as not reliable and precise lifetime cost estimation, which also occurs in the researches with the first deficiency.

Furthermore, a common serious drawback in present researches is that the variable driving situations, state of health (SOH) of power sources and prices of hydrogen and power sources, which affect the optimal cost results and charge sustaining of battery, even more seriously, the normal operation of the vehicle, are totally not considered. The EMS control parameters optimized for specified driving cycles cannot meet all kinds of road situations. The degradation of power sources leads to the decrease of their performances and corresponding degradation rates will change along with SOHs [18]. Prices of hydrogen and power sources will also change along with their technology development on production, usage, investment, and operation. In a word, the constant parameters in the EMSs aiming to improve the economy of FCHEVs cannot meet the dynamical and variable operating conditions of FCHEVs, no matter in the external environment like variable driving conditions and prices or in the internal conditions like degradation and failures.

\section{Main contributions}

To the best knowledge of the authors, no efforts have been made to develop a cost minimization strategy (CMS) to minimize the hydrogen cost and lifetime costs of power sources under variable internal and external conditions on power sources and road situations with adaptive control parameters. In order to bridge this research gap and overcome shortcomings of present researches on improving FCHEVs economy, an OCMS for FCHEVs based on decision making framework considering the dynamical road information, power sources degradation, price evolution of materials is developed. Three main original contributions can be concluded to distinguish our research from other exiting studies.

First, a CMS is built to improve the fuel economy and decrease the lifetime costs of fuel cell and battery based on their degradation models.

Second, a decision making framework, for the first time, is built composed of the driving pattern recognition-enabled decision making (DPRDM), prognostics-enabled decision making (PDM), and price prediction-enabled decision making (PPDM). Based on the DPRDM, real-time driving patterns can

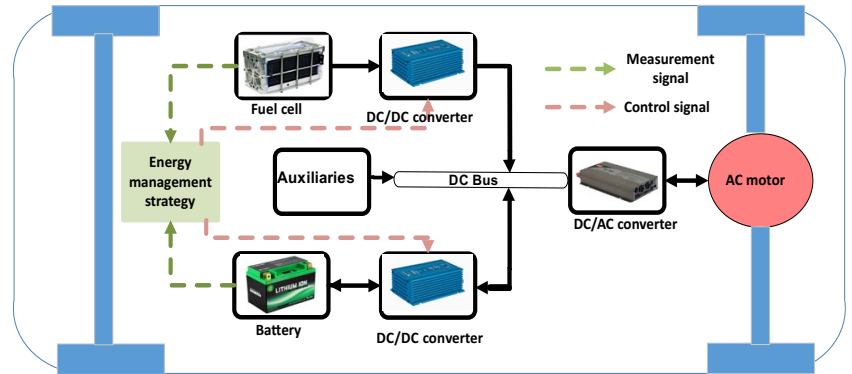

Fig. 1. Power train architecture.

be recognized through the support vector machine (SVM). Based on the PDM, the health states of fuel cell and battery are online estimated based on the unscented Kalman filter (UKF) and are further able to precisely calculate the lifetime costs of power sources cooperating with their empirical degradation models. Through the PPDM, the price evolutions of hydrogen and power sources until the end of the lifetime of the vehicle are projected based on the experience rate approach. Under the innovative decision making framework, the internal and external conditions of the vehicle can be determined.

Third, the pre-optimal equivalent cost factors (ECFs) through the GA are calculated. Based on the recognized diving cycle, estimation of SOHs and price prediction, optimal ECFs and corresponding suitable control policies are adjusted to extend the lifetimes of fuel cell and battery, keep the charge sustaining of battery and achieve the minimization objective of the overall cost.

\section{Organization}

The rest paper is organized as follows: the FCHEV architecture and the models of power sources are presented in Section II. In Section III, the CMS is introduced. The decision making framework including DPRDM, PDM and PPDM is detailed in Section IV. The optimal ECFs determined by GA and simulation results under the OCMS are given in Section V. The effects of driving, degradation, and pricing scenarios on the optimal costs are explored in Section VI. Finally, conclusions are drawn.

\section{VEHICLE MODEL}

In this section, the architecture of FCHEV, adapted from the 2017 Toyota Mirai, is shown in Fig. 1. The main power source is polymer electrolyte membrane fuel cell (PEMFC) and a lithium-ion battery stack assists for the quick dynamical response and recycling braking energy.

\section{A. Powertrain architecture}

As shown in the powertrain architecture of FCHEV, an AC motor is used to drive the vehicle. Fuel cell and battery are connected to the DC bus through a unidirectional DC/DC converter and a bidirectional DC/DC converter respectively to supply the power to the AC motor via a DC/AC inverter. The main specifications of the FCHEV are listed in Table I. The power balance between power sources and power consummation of the FCHEV can be described as [19]:

$$
\begin{gathered}
P_{d}=\left(P_{b}-P_{a u x}\right) \cdot \eta_{a c} \cdot \eta_{\text {motor }} \\
P_{b}=P_{f c} \cdot \eta_{d c f c}+P_{b a} \cdot \eta_{d c b a}
\end{gathered}
$$




$$
\begin{array}{r}
P_{\mathrm{d}}=v\left(m_{v} \frac{d}{d t} v+\frac{1}{2} \rho A C_{x} v^{2}+m_{v} C_{r} g \cos \alpha+\right. \\
\left.m_{v} g \sin (\alpha)\right)
\end{array}
$$

where $P_{d}$ is the required power at wheels to hold the vehicle driving at a certain speed, $P_{b}$ is the supplied power by the fuel cell and battery on DC bus, $P_{a u x}$ is the auxiliary power for the auxiliary components of the vehicle which is taken as a constant value, $\eta_{a c}, \eta_{d c f c}, \eta_{d c b a}$ and $\eta_{\text {motor }}$ are efficiencies, $P_{f c}$ and $P_{b a}$ are the fuel cell and battery power, $v$ is the vehicle speed, $\rho$ is the air density, $m_{v}$ is the vehicle mass, $A$ is the front surface of the vehicle, $g$ is gravitational acceleration, $C_{x}$ is the drag coefficient, $C_{r}$ is the aerodynamic drag coefficient and $\alpha$ is the sloping angle of the road.

\section{B. Fuel cell system model}

1) Electrical model: Fuel cell stack as the core of the fuel cell system transforms the chemical energy into electrical energy through the reaction between hydrogen and oxygen [20]. Many cells compose into a fuel cell stack due to the low voltage of a single cell (approximate 1V). The 370-cells PEMFC with a rated power of $114 \mathrm{~kW}$ is used in the FCHEV. The fuel cell stack voltage can be calculated through the voltage of a single cell multiplied by the number of cells as follows:

$$
E=N\left(E_{\text {rev }}-E_{\text {act }}-E_{\text {ohm }}-E_{\text {con }}\right)
$$

where $N$ is the cell number, $E_{\text {rev }}$ is the thermodynamic reversible potential, $E_{a c t}$ is the activation losses, $E_{\text {ohm }}$ is the ohmic losses, $E_{\text {con }}$ is the concentration losses. These potentials in the static state can be defined as follows:

$$
\begin{array}{lc}
E_{\text {rev }}= & E_{0}-0.85 e^{-3}\left(T-T_{c}\right)+\frac{R T}{2 F} \ln \left(\sqrt{P_{O_{2}}} P_{H_{2}}\right) \\
E_{\text {act }}= & \frac{R T}{2 \alpha F} \ln \left(\frac{I_{f c}}{I_{0}}\right) \\
E_{\text {ohm }}= & I_{f c} R_{f c} \\
E_{\text {con }}= & -B \ln \left(1-\frac{I_{f c}}{I_{m}}\right)
\end{array}
$$

where $E_{0}$ is the reversible nearest potential of a single cell, $P_{\mathrm{O}_{2}}$ and $P_{\mathrm{H}_{2}}$ are the partial pressures of oxygen and hydrogen respectively, $T$ and $T_{C}$ are the temperatures of fuel cell and temperature correction offset respectively, $R$ is the ideal gas constant, $F$ is Faraday constant, $I_{f c}$ is fuel cell current, $\alpha$ is the symmetry factor, $I_{0}$ is the exchange current density, $R_{F C}$ is the internal resistance, $\mathrm{B}$ is an empirical constant, $I_{m}$ is the maximum allowed current.

TABLE I

THE SPECIFICATIONS OF THE VEHICLE AND MAIN COMPONENTS.

\begin{tabular}{ccccc}
\hline \hline & Components & \multicolumn{2}{c}{ Parameters } \\
\hline Vehicle & Mass & $1850 \mathrm{~kg}$ & Front surface & $2.786 \mathrm{~m}^{2}$ \\
PEMFC & Number of cells & 370 & Rated power & $114 \mathrm{~kW}$ \\
Battery & Energy capacity & $1.6 \mathrm{kWh}$ & Nominal voltage & $245 \mathrm{~V}$ \\
\hline
\end{tabular}

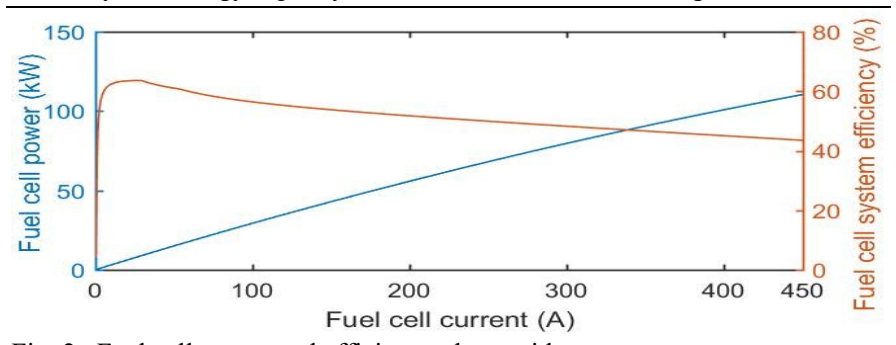

Fig. 2. Fuel cell power and efficiency along with currents.

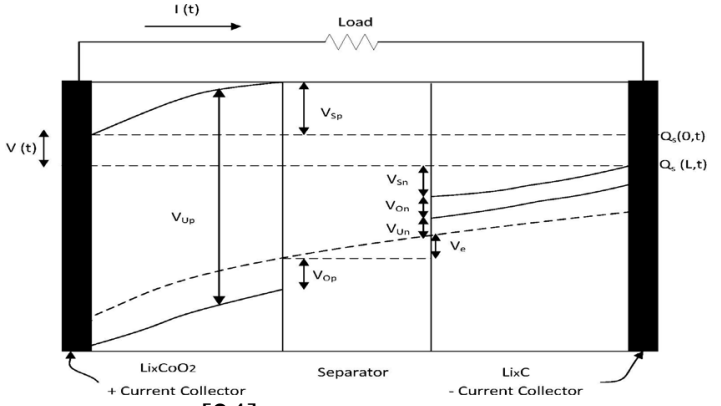

Fig. 3. Battery voltages [24].

The fuel cell output power and system efficiency along with currents are shown in Fig. 2. During the operation process of the fuel cell system, the hydrogen consumption rate $m_{H 2}$ can be defined as:

$$
m_{H 2}=\int_{0}^{t} \frac{M_{H_{2}} N}{2 F} I_{f c}(t) d t
$$

where $\mathrm{t}$ is the operating time of the fuel cell system, $M_{\mathrm{H}_{2}}$ is the hydrogen molar mass, $\mathrm{N}$ is the cell number, $\mathrm{F}$ is the Faraday constant.

2) Degradation model: Along with the operation of power sources, their degradation is unavoidable. For the fuel cell, the degradation concerns many aspects: catalyst layer degradation, membrane degradation, and gas diffusion layer degradation, leading to the decrease of fuel cell voltage and output power over the same amount of hydrogen input. Minimizing fuel cell degradation to achieve the economic objective is one of the most important objectives of EMS. In order to quantify the degradation's cost of the fuel cell, its degradation model to calculate its degradation rates under different operations is built.

In [21], the operation of fuel cell is divided into four operating conditions: the start/stop cycle, load changing cycle, idling mode, and high power mode. Their degradation rates are defined as constant values. Based on the research of $[22,23]$ on the degradation rates of fuel cell tested in automotive conditions, the fuel cell decay rates and currents have a quadratic relationship. Besides, the start/stop cycle leads to a predominately comparable increase of fuel cell degradation. Therefore, an "always-on strategy" is taken to fuel cell to increase its lifetime. The fuel cell empirical degradation model along with its operating conditions, adapted from [21], is built as:

$$
V^{\prime}=k\left(\left(a \cdot I_{f c}^{2}+b \cdot I_{f c}+c\right) \cdot t+V_{4}^{\prime} \cdot n_{2}\right)
$$

where $\mathrm{a}, \mathrm{b}$ and $\mathrm{c}$ are fitting coefficients, $\mathrm{t}$ is the sampling time, $V_{4}^{\prime}$ is the degradation rate under load changing condition, $n_{2}$ is the rapid load-changing cycle time.

\section{Battery model}

1) Electrochemistry model: A lithium-ion battery pack with 198 cells with a nominal capacity of $1.6 \mathrm{kWh}$ is used as the ESS of the FCHEV. An electrochemistry-based battery model in the cell level based on [24] is built to estimate its voltage as a function of time given the current drawn from the battery. The battery is composed of positive and negative electrodes and electrolyte. The cell's overall voltage is decided by the potential difference between the positive current collector $Q_{s}(0, t)$ and the negative one $Q_{s}(L, t)$ minus resistance losses. The cell's potential contributed by several electrochemical 
processes is shown in Fig. 3. The detailed modeling process can be found in [24]. The relationship between battery output voltage $V(t)$ and different potentials can be expressed as:

$$
V(t)=V_{U, p}-V_{O, p}-V_{U, n}-V_{O, n}-V_{r}
$$

where $V_{U, p}$ and $V_{U, n}$ are the equilibrium potentials, $V_{O, p}$ and $V_{O, n}$ are the surface potentials, $V_{r}$ is the ohmic potential due to the ohmic resistance at the solid-phases $\left(V_{S, p}\right.$ and $\left.V_{S, n}\right)$, electrolyte $\left(V_{e}\right)$ and current collectors ( $V_{c c, p}$ and $\left.V_{c c, n}\right)$. Subscript $p$ and $n$ represent positive and negative respectively.

Equilibrium potential of each electrode is decided by the amount of charge in the electrodes as:

$$
\begin{array}{cc}
V_{U, i}= & U_{0}+\frac{R T}{n F} \ln \left(\frac{1-x_{i}}{x_{i}}\right)+V_{a c t, i} \\
V_{a c t, i}= & \frac{1}{n F}\left(\sum_{k=0}^{N_{i}} A_{i, k}\left(\left(2 x_{i}-1\right)^{k+1}-\frac{2 x_{i} k\left(1-x_{i}\right)}{\left(2 x_{i}-1\right)^{1-k}}\right)\right)
\end{array}
$$

where $U_{0}$ is the reference voltage, $\mathrm{T}$ is the electrode temperature, $n$ is the number of electrons transferred in the reaction, $V_{a c t, i}$ is the activity coefficient term, $A_{i, k}$ is the empirical coefficient, $i$ represents subscript $\mathrm{p}$ or $\mathrm{n}$.

Surface overpotential $V_{O, i}$ and ohmic overpotential $V_{r}$ can be calculated as:

$$
\begin{array}{cc}
V_{O, i}= & \frac{R T}{F \alpha} \arcsin \left(\frac{J_{i}}{2 J_{i 0}}\right) \\
V_{r}= & i_{a p p} R
\end{array}
$$

where $\alpha$ is the symmetry factor, $J_{i}$ is the current density, $J_{i 0}$ is the exchange current density, $R$ is the constant resistance.

The battery SOC is defined as the charge fraction of the negative electrode and the whole battery as:

$$
S O C=\frac{q_{n}}{0.6 q_{\max }}
$$

where $q_{n}$ is the amount of $\mathrm{Li}$ ions in the negative electrode, $q_{\max }$ is the total amount of Li ions.

2) Degradation model: The battery degradation process is complicated and influenced by many factors like time, temperature, discharge rate, depth of discharge [25]. An empirical degradation model adapted from [26] is used to quantify battery degradation including calendar aging and cycle aging. The whole capacity loss $\mathrm{Q}_{\text {loss }}$ including the capacity loss $\mathrm{Q}_{\text {loss }}^{\text {calendar }}$ due to the calendar aging and the capacity loss $\mathrm{Q}_{\text {loss }}^{\text {cycle }}$ due to the cycle aging is defined as :

$$
\begin{array}{cc}
Q_{\text {loss }} & =Q_{\text {loss }}^{\text {cycle }}+Q_{\text {loss }}^{\text {cycle }} \\
Q_{\text {loss }}^{\text {calendar }} & =A t^{0.5} e^{\frac{-E_{A}}{R T}} \\
Q_{\text {loss }}^{\text {cycle }} & =\left(a T^{2}+b T+c\right) e^{(d T+e) I_{\text {rate }}} A h_{\text {to }}
\end{array}
$$

where $A, a, b, c, d$ and $e$ are the coefficient factors, $E_{A}$ is the activation energy, $R$ is the gas constant, $T$ is the absolute temperature, $t$ is time, $I_{\text {rate }}$ is the charging/discharging rate expressed as C-rate, $A h_{\text {to }}$ is the Ah-throughout.

\section{COST MINIMIZATION STRATEGY}

In this section, the composition of CMS as the basis of OCMS is introduced, including the objective function and constraints.

\section{A. Cost objective}

The objective of CMS is to minimize the overall operating cost of FCHEV including hydrogen cost, fuel cell, and battery lifetime costs. The overall cost $C_{\text {whole }}$ in the online sampling time $\Delta t$ can be defined as:

$$
C_{\text {whole }}=C_{H 2}+C_{f c}+C_{b a}+C_{S O C}+C_{p e n}
$$

where

1) $C_{H 2}$ is the hydrogen cost, calculated based on the hydrogen price $\phi_{h 2}$ and hydrogen consumption $m_{H 2}$ at $\Delta t$ as:

$$
C_{H 2}=\phi_{h 2} m_{H 2}
$$

2) The fuel cell lifetime $\operatorname{cost} C_{f c}$ and battery lifetime $\operatorname{cost} C_{b a}$ can be calculated based on the fuel cell price per unit of power $\phi_{f c}$, fuel cell nominal power $P_{n f c}$, battery price per unit of energy $\phi_{b a}$, battery nominal energy $E_{n b a}$ and corresponding $\mathrm{SOH}$ decreases in $\Delta t$ as follows:

$$
\begin{gathered}
C_{f c}=\phi_{f c} P_{n f c} \Delta S o h_{f c}=\phi_{f c} P_{n f c} \frac{V^{\prime}}{\Delta V} \\
C_{b a}=\phi_{b a} E_{n b a} \Delta S o h_{b a}=\phi_{b a} E_{n b a} \frac{Q_{l o s s}}{Q_{t a r}}
\end{gathered}
$$

$\Delta S o h_{f c}$ and $\Delta S o h_{b a}$ are instantaneous losses of their SOHs, $\Delta V$ is the voltage drop criteria for the end of the lifetime of fuel cell (10\% voltage decrease), $Q_{t a r}$ is the charge loss criteria for the end of the lifetime of battery (20\% capacity losses).

3) $C_{S O C}(t)$ is the battery sustaining charging cost. Due to the hybrid architecture of FCHEV drivetrain, the charge sustaining of battery is required meaning that the battery SOC at the end of driving cycles should be equal to its initial one. The charging sustaining objective of CMS is pursued through $C_{S O C}$, which is added as the penalty cost in the objective function. When battery SOC at sampling time $t$ is less than the initial SOC, $C_{S O C}$ is defined as the sum of the hydrogen consumption $\operatorname{cost} C_{\mathrm{H} 2}^{p}$, fuel cell and battery aging $\operatorname{costs} C_{f c}^{p}$ and $C_{b a}^{p}$ during the hypothetically charging process of battery back to initial SOC by fuel cell at its maximum efficiency point, as:

$$
C_{S O C}(\mathrm{t})=\lambda_{S O C}\left(C_{H 2}^{p}+C_{f c}^{p}+C_{b a}^{p}\right)
$$

The calculation of penalty costs is the same as (13). $\lambda_{S O C}$ is the equivalent cost factor (ECF) for the battery sustaining charge.

4) $C_{\text {pen }}$ is the battery SOC penalty cost to limit its SOC range, defined as:

$$
C_{\text {pen }}=\left\{\begin{array}{c}
0, S O C_{\min }<S O C<S O C_{\max } \\
+\infty, S O C \geq S O C_{\min }, S O C \leq S O C_{\max }
\end{array}\right.
$$

when battery SOC is greater than the maximum SOC $S O C_{\max }(0.85)$ or less than minimum SOC $S O C_{\min }(0.45)$, a very large value is added to the objective function to avoid the overcharge or over-discharge of battery.

\section{B. Constraints}

Some constraints are set for the optimal control problem to make sure the normal operation of the vehicle and prolong the lifetime of power sources. The above objective function and constraints of CMS can be defined as:

$$
\begin{aligned}
& \text { Min } f_{w}(t)=C_{w h o l e} \\
& I_{f c}^{\min } \leq I_{f c} \leq I_{f c}^{\max } \\
& I_{b a}^{\min } \leq I_{b a} \leq I_{b a}^{\max } \\
& -d I_{f c} \leq \frac{I_{f c}(t)-I_{f c}(t-1)}{T} \leq d I_{f c}
\end{aligned}
$$

Fuel cell current range $\left(I_{f c}^{\min }: 0 \mathrm{~A}, I_{f c}^{\max }: 450 \mathrm{~A}\right)$, battery current range $\left(I_{b a}^{\min }:-150 \mathrm{~A}, I_{b a}^{\max }: 150 \mathrm{~A}\right)$, and fuel cell 
dynamical change rate $\left(d I_{f c}: 100 \mathrm{~A} / \mathrm{s}\right)$ are limited through constraints. Sequential quadratic programming generates steps by solving quadratic subproblems and is particularly good at solving problems with significant nonlinearity. Therefore, it is used to solve this non-line constrained local optimization problem of CMS.

\section{DECISION MAKING FRAMEWORK}

The uncertainties on the variable road information, health and failure states of drivetrain components, and prices of fuel and power sources bring a big challenge to the optimal results of minimizing the operating cost of FCHEVs and charge sustaining of battery. To solve this problem, a decision making framework, including DPRDM, PDM and PPDM to recognize the dynamical driving pattern, estimate the health state and project the future price, cooperating with CMS and making decisions to extend the lifetime of power sources and reduce the overall cost of the FCHEV is built. The general architecture of the decision making framework is shown in Fig. 4.

\section{A. Driving pattern recognition-enabled decision making}

The core of the DPRDM is the driving pattern recognition, which is to sample and extract feature parameters from a period of past driving profiles. Then the well-trained classifiers are used to recognize the current driving patterns [27]. Based on the recognized driving pattern, the right decisions on optimal control parameters can be made.

10 parameters of driving profiles are chosen to recognize the driving patterns, including max speed, average speed, max acceleration, max deceleration, average acceleration, average deceleration, idle time factor (idle time/total time), low-speed factor (low-speed time/total time), mid-speed factor (mid-speed time/total time), high-speed factor (high-speed time/total time). The low, mid, and high speeds are defined as the speed less than $40 \mathrm{~km} / \mathrm{h}$, between $40 \mathrm{~km} / \mathrm{h}$ to $80 \mathrm{~km} / \mathrm{h}$, and higher than $80 \mathrm{~km} / \mathrm{h}$ respectively. Support vector machine (SVM) shows good results in the classification technique on medical diagnostics, optical character recognition, electric load forecasting and other fields. Therefore, it is used in the driving cycle recognition in this paper. The SVM belongs to the supervised machine learning and its architecture is shown as Fig. 5. The SVM is composed of the input layer, hidden layer, and output layer. Each layer has many proceeding units and parameterized by a weight vector $(\mathrm{w})$ and a bias (b). The output y can be calculated through the hidden layer and corresponding weight vectors and biases. The LIBSVM software developed by [28] is used to the driving pattern recognition.

The driving situation can be divided into urban, suburban and highway conditions. Two typical driving cycles are chosen respectively for three driving conditions (NYCC and MANHATTAN for urban condition, WVUSU and CSHV for suburban condition, and US06-HWY and HWFET for highway condition). The 10 parameters of six typical driving cycles are taken as the input variables and used to train the SVM. Based on the vehicle traveling parameters and trained SVM model, the current driving category can be classified into 1 to 6 corresponding to six typical driving cycles. $\gamma$, the kernel width of SVM kernel function and penalty coefficient $\mathrm{C}$ are vital parameters for SVM, affecting recognition accuracy. GA as one of the commonly used optimization algorithms is chosen to

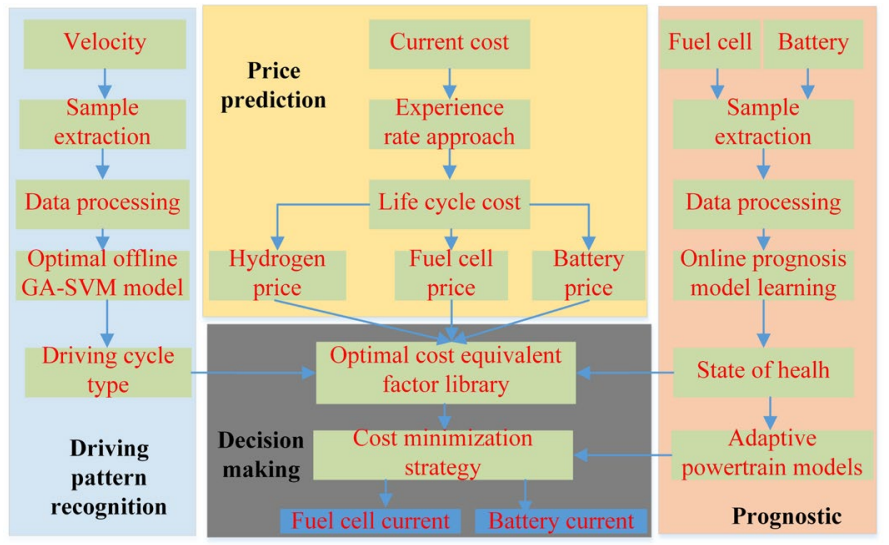

Fig. 4. Decision making framework of energy management strategy Input Layer Hidden Layer Output Layer

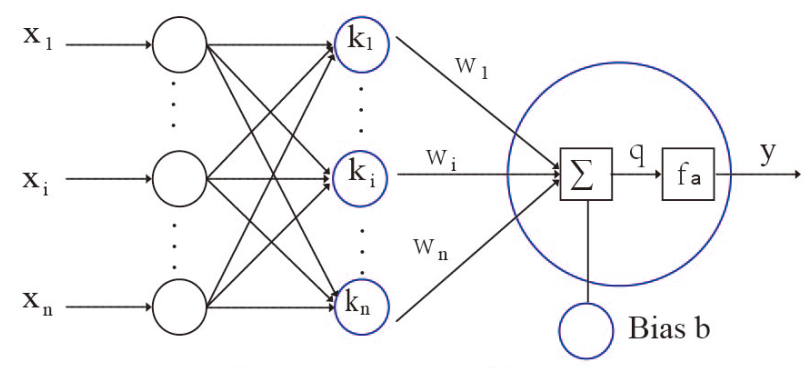

Support vector machine

Fig. 5. The architecture of the SVM

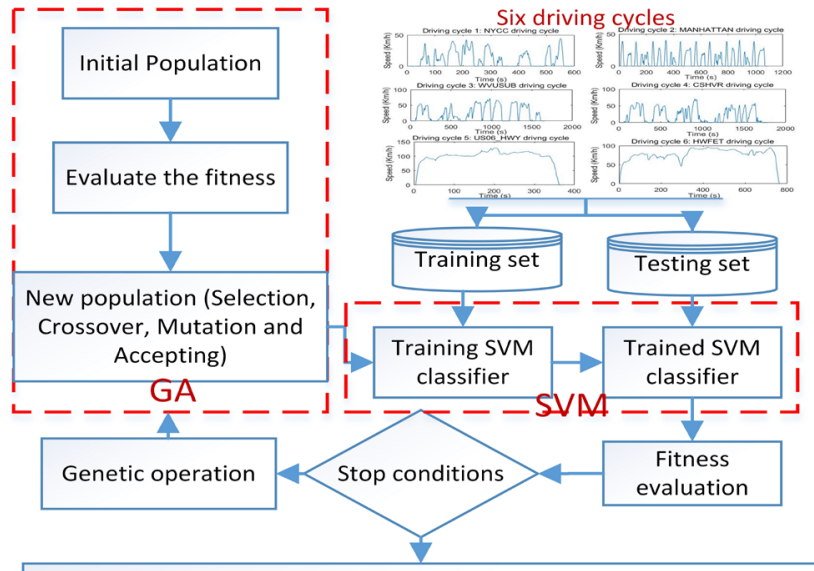

Optimized parameters Corresponding GA optimized SVM model

Fig. 6. Optimal GA-SVM model for driving cycle recognition

optimize the parameters $\gamma$ and $\mathrm{C}$ to improve recognition accuracy. The process of GA based SVM for driving cycle recognition is shown in Fig. 6. Based on the optimal GA-SVM model and collected online vehicle speed, the driving pattern of the vehicle can be decided.

\section{B. Price prediction-enabled decision making}

The wide deployment of FCHEVs and the building of hydrogen stations in the following decades, the hydrogen, fuel cell, and battery prices will change along with time, which are important parameters for CMS. Experience curves as the core of PPDM describing the development of production cost as a function of increased cumulative production accounting for all cost factors (sales, research, production, depreciation and so on) is used to project their future prices.

Experience curves can be derived based on Wright's law using historic product prices and cumulative installed 
capacities in the long term analysis. The product price tends to decrease by a constant percentage for each doubling of cumulative deployments such as the cumulative installed energy or power capacity of fuel cell and battery. This phenomenon can be described as:

$$
\begin{aligned}
C_{t} & =C_{0} X^{-b} \\
E R & =1-2^{-b}
\end{aligned}
$$

where $C_{t}$ and $C_{0}$ are the capital costs at the time $t$ and initial one respectively, $\mathrm{b}$ is the experience rate, $E R$ is the learning rate representing the price reduction for each doubling of the installed capacity, $X$ is the ratio of cumulative production at $\mathrm{t}$ $Q_{t}$ and initial one $Q_{0}$ defined as:

$$
X=\frac{Q_{t}}{Q_{0}}
$$

The published experience curves from peer-reviewed literature, research, and industry reports and software are used in this paper.

1)Hydrogen price: Hydrogen can be produced through many pathways like coal gasification, steam reforming of methane, biomass gasification, and water electrolysis. Natural gas reforming and on-site electrolysis as two main pathways are considered in this study. The final hydrogen price from hydrogen station can be calculated based on the cost of hydrogen production, delivering and dispensing as:

$$
\phi_{h 2}=\frac{5 \sum_{1}^{4} \frac{C A+V A+O P}{A H P}}{n}
$$

where $\phi_{h 2}$ is the hydrogen prices from stations, $C A$ is the capital costs, $V A$ is the annuitized expense, $O P$ is the operational cost, $A H P$ is the annual hydrogen production, $n$ is the station lifetime. Based on the research [29], the hydrogen overall price can be determined, shown in Fig. 7. The overall price firstly decreases and latterly holds at a certain price and gets a little bit increase, which is mainly due to the increasing percentage share of electrolysis.

2)Battery and fuel cell prices: In order to project the price reductions of battery and fuel cell, the market diffusion processes of technologies are calculated based on the archetypal sigmoid function (S-curve), which has been widely used on the deployment of several technologies. The installed nominal capacity of battery based on the logistic growth function is shown as:

$$
C_{n}=\frac{C_{m}}{1+\frac{\left(C_{m}-C_{b}\right)}{C_{b}} e^{-r n}}
$$

where $C_{n}$ is the annual installed battery capacity, $C_{m}$ and $C_{b}$ are the maximum and initial annual installed battery capacity, $\mathrm{n}$ is the number of years from the initial year, $r$ is the growth rate determined by statistical data from research reports. Based on (25) and (24), the cumulated battery capacity and future price are projected in Fig. 8. Based on the learning rate 18\% from [30] and the ultimate cost $30 \$ / \mathrm{kW}$ from [31], the fuel cell system price and accumulated FCHEV number are shown in Fig. 9.

\section{Prognostics-enabled decision making}

PDM is an emerging research area that can help increase the durability of power sources. The health information received from the estimation of the present degradation state and the prediction for the future operating conditions is intergraded into making decisions in the process of selecting subsequent actions of power sources. In this paper, the degradation of power sources is estimated and the optimal control parameters of EMS

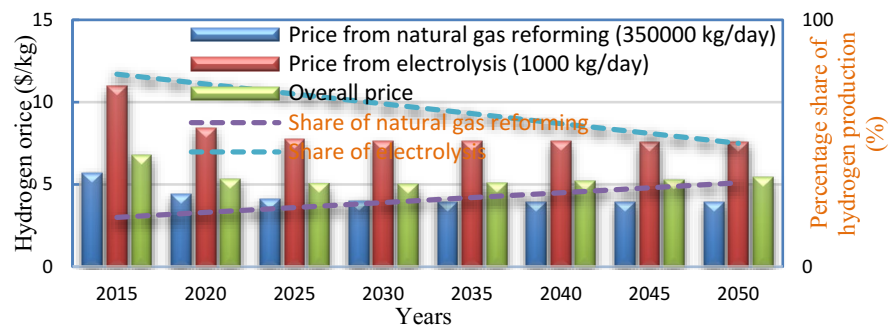

Fig. 7. Future hydrogen cost relative time

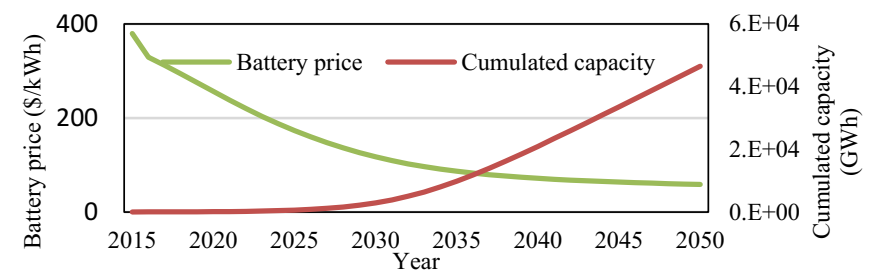

Fig. 8. Cumulated battery capacity and price along with time

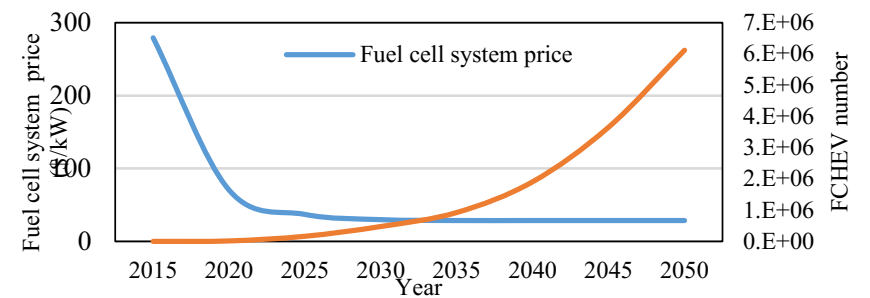

Fig. 9. Cumulated FCHVE number and fuel cell system price along with time are adjusted to achieve the optimal objective. Besides, although empirical degradation models of fuel cell and battery work well to estimate their degradation costs in their initial usages, limited by the dynamical operation and variable external environment, the empirical model cannot accurately depict the degradation rates in the following aging. PDM can help to overcome this shortcoming from empirical models. The discrepancy between the real-life situation and laboratory aging testing could be addressed. In this section, the battery and fuel cell SOHs are online estimated, and the empirical degradation model of fuel cell and battery could be updated to increase their accuracies.

The prognostic model is very nonlinear. Therefore, a nonlinear filter is required. The unscented Kalman filter (UKF) has higher accuracy than extended Kalman filter and a lower computational cost than particle filter. Therefore, UKF is chosen to estimate the SOHs of fuel cell and battery.

1) Fuel cell SOH: Based on [32], the resistance $R_{f c}$ and maximum current $I_{m}$ in (5) of the fuel cell model evolve significantly along with aging. Their variations along with time can be expressed as:

$$
\begin{array}{cc}
R_{f c}(t)= & R_{f c 0}(1+\alpha(t)) \\
I_{m}(t)= & I_{m 0}(1-\alpha(t)) \\
\alpha(t) & =\int_{0}^{t} \beta \cdot d t
\end{array}
$$

where $R_{f c 0}$ and $I_{m 0}$ are initial resistance and maximum allowed current, $\alpha(t)$ is the degradation degree, $\beta$ is the degradation rate. Based on the imputed current and measured voltage values, UKF can jointly estimate $\alpha$ and $\beta$. The fuel cell $\mathrm{SOH}$ can be estimated through

$$
\operatorname{Soh}_{f c}(t)=\frac{\alpha(t)}{\alpha_{\max }}
$$

where $\alpha_{\max }$ is the maximum degradation degree corresponding to the $10 \%$ voltage decrease. 
Fuel cell degradation under variable loads is used to verify the effectiveness of the online prognostic model. The fuel cell current profile and results of fuel cell output voltage through UKF are shown in Fig. 10. The corresponding simulated and estimated degradation parameters are shown in Fig. 11. It can be observed that online prognostic can precisely estimate the fuel cell voltage and degradation parameters.

2) Battery SOH: The degradation parameters of battery model: maximum charge of battery $q_{\max }$, battery resistance $R$ and the diffusion rate $D$ are taken as the state parameters of the prognostic model. Their change rates of these parameters along with battery current $I_{b a}$ can be expressed as:

$$
\begin{aligned}
q_{\max }^{\prime} & =w_{q}\left|I_{b a}\right| \\
R^{\prime} & =w_{R}\left|I_{b a}\right| \\
D^{\prime} & =w_{D}\left|I_{b a}\right|
\end{aligned}
$$

where $w_{q}, w_{R}$ and $w_{D}$ are aging rate parameters.

Based on the UKF, the charge/discharging battery current and observed voltages, these state parameters can be estimated. The SOH of the battery can be estimated through

$$
\operatorname{Soh}_{b a}(t)=\frac{q_{\max }(t)}{q_{\max }^{\text {int }}}
$$

where $q_{\text {max }}^{\text {int }}$ is the initial maximum charge.

The experimental test data under random charge/discharge current profile is used to test the online prognostic algorithm. The battery voltages, estimated $q_{\max }$ and corresponding $Q_{\text {loss }}$ from UKF are shown in Fig. 12 and Fig. 13. It can be observed that online prognostic can precisely estimate the battery voltage and degradation parameters.

\section{D.OCMS based on decision making framework}

Based on the DPRDM model, the real driving situation can be recognized as corresponding driving patterns. Based on the PPDM, the prices of hydrogen, fuel cell and battery for the following decades can be projected. Based on the PDM, the SOHs and degradation parameters of fuel cell and battery can be precisely estimated. These important factors affect the charging sustaining of battery and optimal cost results, therefore the optimal control parameter: ECF of CMS is offline optimized by GA based on decision making framework to be used in the online application of CMS on vehicles, defined as OCMS.

\section{VALIDATION AND RESULT ANALYSIS}

Variable driving cycles, health states, and prices can compose many situations. The validation of OCMS is conducted under the Combined UDDS and UNIF01 driving cycles (CUU). Three degradation conditions of fuel cell and battery (D1, D2, and D3) and three price conditions on the year 2020, 2025 and 2030 (P1, P2, and P3) are chosen as the examples of different aging states and prices. Three situations under the CUU driving cycle are set as situation 1 (S1) under D1 and P1, situation 2 (S2) under D2 and P2, and situation 3 (S3) under D3 and P3, shown in Table III. The optimal ECFs for three situations under six typical driving cycles (from 1 to 6 ) can be got through GA as Table IV.

Based on the optimal ECFs under different situations, the ECFs can be automatically adjusted through the decision making framework to seek for the optimal results on the overall cost and the charging sustaining. Based on the DPRDM, the

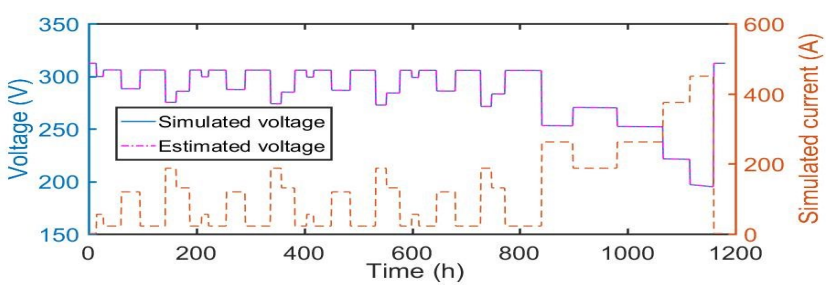

Fig. 10. Fuel cell current and voltages.

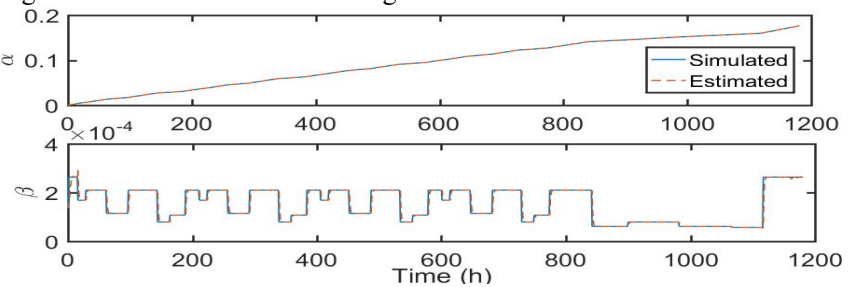

Fig. 11. Degradation parameter $\alpha$ and $\beta$.

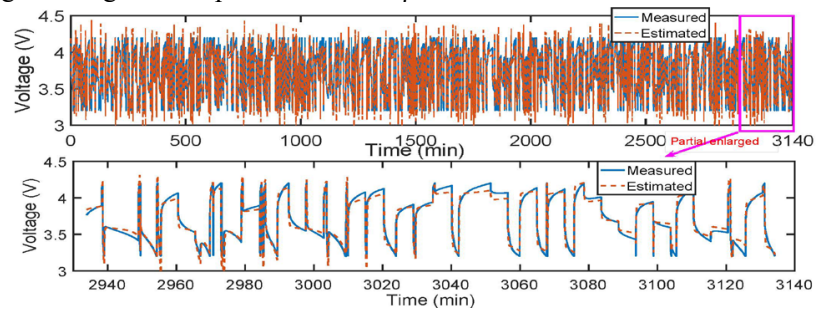

Fig. 12. Estimated and measured battery voltages through UKF.

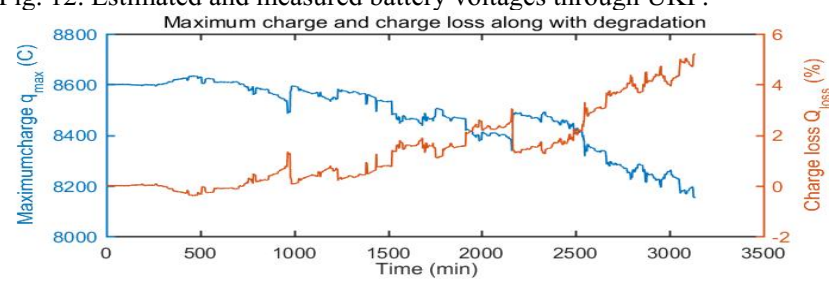

\begin{tabular}{|c|c|c|c|c|c|c|c|}
\hline \multirow[t]{2}{*}{ States } & \multicolumn{3}{|c|}{ Degradation } & \multicolumn{4}{|c|}{ Prices } \\
\hline & & $\operatorname{Soh}_{f c}$ & $\operatorname{Soh}_{b a}$ & & $\begin{array}{c}\phi_{h 2} \\
(\$ / \mathrm{kg})\end{array}$ & $\begin{array}{c}\phi_{f c} \\
\$ / \mathrm{kW}\end{array}$ & $\begin{array}{c}\phi_{b a} \\
(\$ / \mathrm{kWh})\end{array}$ \\
\hline $\mathrm{S} 1$ & D1 & 1 & 1 & $\mathrm{P} 1$ & 5.32 & 70.41 & 256 \\
\hline $\mathrm{S} 2$ & D2 & 0.5 & 0.5 & $\mathrm{P} 2$ & 5.05 & 37.00 & 173 \\
\hline $\mathrm{S} 3$ & D3 & 0.1 & 0.1 & P3 & 5.03 & 29.84 & 117 \\
\hline
\end{tabular}

Fig. 13. Maximum charge and charge loss along with battery degradation. TABLE III

THE SIMULATION SITUATIONS.

THE OPTIMAL ECFS FOR SIX DRIVING CYCLES UNDER THREE SITUATIONS.

\begin{tabular}{ccccccc}
\hline \hline & 1 & 2 & 3 & 4 & 5 & 6 \\
\hline S1 & 0.621 & 9.632 & 1.214 & 16.502 & 18.042 & 2.207 \\
S2 & 1.453 & 6.620 & 10.382 & 8.988 & 11.333 & 3.528 \\
S3 & 0.200 & 5.931 & 7.236 & 9.799 & 10.488 & 11.790 \\
\hline
\end{tabular}

driving pattern of the CUU driving cycle can be recognized as Fig. 14. Two-time factors for the DPRDM combined with the moving windows should be mentioned for the recognition process. Time length of moving horizon for historical data to identify the current driving pattern and the duration of output recognized pattern are set $60 \mathrm{~s}$ and 10 s respectively. Once the pattern of the driving cycle is obtained, the corresponding ECF is selected from the pre-optimized library until the next prediction time.

The comparative simulation results for CMS with constant ECF labeled as CMS and OCMS with adaptive ECF under three situations are shown in Table V. It should be mentioned that in order to make a fair comparison, in addition to the overall cost at the end of the driving cycle, the final battery SOC variation should also be considered in the overall cost 
through the added battery sustaining charging cost in (17). It can be observed compared to CMS (ECF $=0.621)$, that overall costs of OCMS have increased $0.9 \%, 1.9 \%$ and $15 \%$ for S1, S2, and S3 respectively. The charge sustaining of battery is well respected by OCMS through observed similar SOC at the end of the driving cycle, but this objective is not achieved by CMS. The decreasing overall costs from S1 to S3 are due to the reduced prices of hydrogen, fuel cell and battery along with time.

The hydrogen consumption cost, fuel cell lifetime cost, battery lifetime cost, overall cost, and battery SOC along with the driving cycle under S1 for OCMS are shown in Fig. 15. The battery degradation cost is the largest, compared to hydrogen and fuel cell degradation. Battery SOC is also in a limited range. The power splits along with the driving cycle under S1 for OCMS are shown in Fig. 16. The fuel cell mostly operates at low power. The dynamical variation of load power is largely supplied by battery. Fuel cell and battery also both work in the limited power range.

\section{DRIVING, DEGRADATION AND PRICING IMPACT}

In the above section, the optimization results of three situations are analyzed and the validation of OCMS is proved. In this section, the sensitivity analysis of driving, degradation, and pricing scenarios on the final optimization results is elucidated.

\section{A. Driving impact}

In addition to CUU driving cycle, another two driving cycles i.e., LA92 and SC03 driving cycle with the same degradation and pricing state (D1 and P1 in Table III) are considered. The optimization results of the classification, power split and battery SOC are shown in Fig. 17. The driving time and distance of LA92 and SC03 driving cycle are $1435 \mathrm{~s}, 15.8 \mathrm{~km}$ and $600 \mathrm{~s}, 5.76 \mathrm{~km}$, respectively, leading to two-time scale optimization results in Fig. 17. It can be observed that the fuel cell and battery both work normally to meet the speed requirement of the driving cycle. The battery SOCs are also in the limited range. The validation of the SVM classification and OCMS is proved through different driving cycles.

Through the comparison of validations under three driving cycles, the effects of driving cycles on the operating cost can be observed. The comparison of optimal costs of hydrogen, fuel cell and battery lifetime cost in $\$ / \mathrm{km}$ are shown in Fig. 18. It can be observed that the $\mathrm{SC} 03$ driving cycle has the highest overall cost, about $1 \$ / \mathrm{km}$ (increases $34.04 \%$ compared to the CUU driving cycle). The expanse of the LA92 driving cycle is similar to the CUU driving cycle. The fuel cell lifetime cost takes the largest share over three cycles, due to its short lifetime and high price.

\section{B. Degradation impact}

The degradation impact on the optimal costs under the same price state (P1) and CUU driving cycle are examined. The cost results under three degradation states (D1, D2 and D3 in Table III) are shown in Fig. 19.

It can be observed that the OCMS under D3 has the least overall cost of $27.88 \$(9.5 \%$ and $8.8 \%$ reductions versus D2 and D1 respectively). Along with the degradation of fuel cell and battery, the overall cost has a slight increase firstly from D1

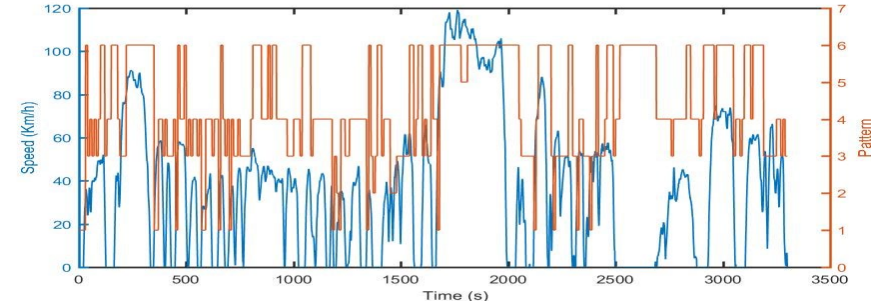

Fig. 14. Driving pattern recognition results for the CUU driving cycle TABLE V

COMPARATIVE RESULTS FOR EMSS UNDER THREE DIFFERENT SITUATIONS

\begin{tabular}{lcccccc}
\hline & \multicolumn{2}{c}{ S1 } & \multicolumn{2}{c}{ S2 } & \multicolumn{2}{c}{ S3 } \\
& CMS & OCMS & CMS & OCMS & CMS & OCMS \\
\hline Overall cost (\$) & 30.85 & 30.57 & 21.64 & 21.23 & 16.37 & 13.90 \\
$\begin{array}{l}\text { Fuel cell } \\
\text { lifetime cost (\$) }\end{array}$ & 8.33 & 9.19 & 4.95 & 5.13 & 3.60 & 4.54 \\
$\begin{array}{l}\text { Battery lifetime } \\
\text { cost (\$) }\end{array}$ & 19.64 & 18.54 & 13.49 & 13.24 & 9.68 & 6.36 \\
$\begin{array}{l}\text { Hydrogen cost } \\
\text { (\$) }\end{array}$ & 2.88 & 2.84 & 3.2 & 2.86 & 3.09 & 3.00 \\
Battery soc & 0.740 & 0.800 & 0.728 & 0.799 & 0.695 & 0.788 \\
\hline
\end{tabular}

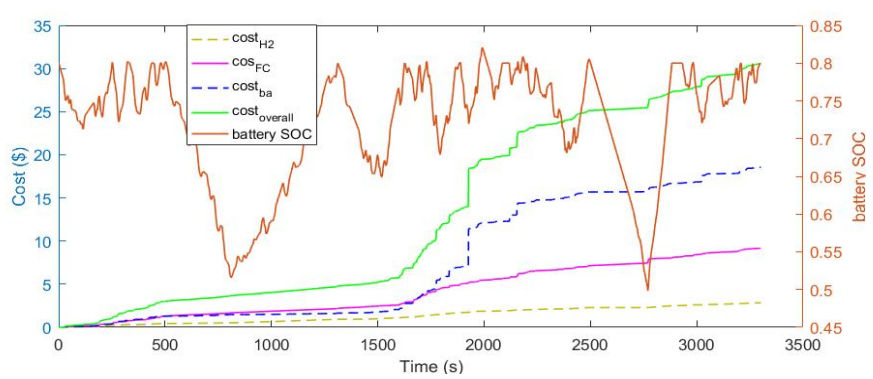

Fig. 15. Optimal cost and battery SOC
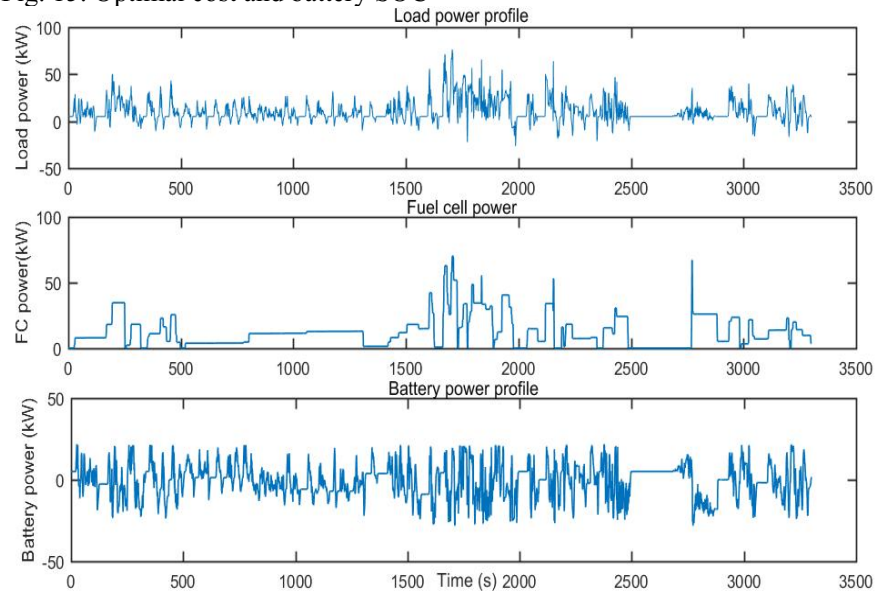

Fig. 16. Optimal power split

to D2 and then decreases to the least value. The difference between D1 and D2 over the lifetime costs of the fuel cell and battery is very small. The final battery SOC of D1 and D2 are 0.8 and 0.77 respectively, which is the main reason for the difference in overall cost. The degradation of power sources from D2 to D3 leads to the more frequent utilization of fuel cell and the decrease of battery lifetime cost and overall cost.

\section{Pricing impact}

The pricing impact of hydrogen, fuel cell, and battery are analyzed under the same driving cycle (CUU driving cycle) and degradation state (D1). The optimization results under different pricing states (P1, P2 and P3 in Table III) are shown in Fig. 20.

Based on the hydrogen price model, the hydrogen price will decrease by $5 \%$ from $\mathrm{P} 1$ to $\mathrm{P} 2$ and the hydrogen price of $\mathrm{P} 2$ is almost equal to P3. The fuel cell and battery prices will 
gradually decrease along with the year. It can be obviously observed the gradual decrease in overall cost. Compared to P1, the decrease has reached $37.2 \%$ and $57 \%$ respectively for $\mathrm{P} 2$ and P3, due to the prices decrease. Along with the decreasing trend of hydrogen and power sources prices, the FCHEVS under the designed OCMS will be more competitive to the vehicles with an internal combustion engine.

\section{CONCLUSION}

This paper developed a cost optimal, decision making energy management strategy considering the fuel cell and battery lifetimes and the uncertainness on the driving pattern, degradation states of power sources, and prices of fuel and drivetrain components. The overall cost including the hydrogen cost, fuel cell and battery degradation cost was minimized. The decision making framework was built to supply optimal equivalent cost factors at all kinds of situations on the driving pattern, health state and price. Simulation results proved that the optimal cost and charger sustaining of battery were achieved through the cooperation between CMS and decision making framework composing the OCMS.

\section{REFERENCES}

[1] Amin, R. T. Bambang, A. S. Rohman, C. J. Dronkers, R. Ortega, and A. Sasongko, "Energy Management of Fuel Cell/Battery/Supercapacitor Hybrid Power Sources Using Model Predictive Control," IEEE Transactions on Industrial Informatics, vol. 10, no. 4, pp. 1992-2002, 2014.

[2] Y. Xing, J. Na, and R. Costa-Castelló, "Real-Time Adaptive Parameter Estimation for a Polymer Electrolyte Membrane Fuel Cell," IEEE Transactions on Industrial Informatics, vol. 15, no. 11, pp. 6048-6057, 2019.

[3] H. Li, A. Ravey, A. N'Diaye, and A. Djerdir, "A novel equivalent consumption minimization strategy for hybrid electric vehicle powered by fuel cell, battery and supercapacitor," Journal of Power Sources, vol. 395, pp. 262-270, 2018.

[4] T. Liu, H. Yu, H. Guo, Y. Qin, and Y. Zou, "Online Energy Management for Multimode Plug-In Hybrid Electric Vehicles," IEEE Transactions on Industrial Informatics, vol. 15, no. 7, pp. 4352-4361, 2019.

[5] K. Jia, Y. Chen, T. Bi, Y. Lin, D. Thomas, and M. Sumner, "Historical-Data-Based Energy Management in a Microgrid With a Hybrid Energy Storage System," IEEE Transactions on Industrial Informatics, vol. 13, no. 5, pp. 2597-2605, 2017.

[6] J. P. Torreglosa, P. García, L. M. Fernández, and F. Jurado, "Predictive Control for the Energy Management of a Fuel-Cell-BatterySupercapacitor Tramway," IEEE Transactions on Industrial Informatics, vol. 10, no. 1, pp. 276-285, 2014.

[7] H. Li, A. Ravey, A. N'Diaye, and A. Djerdir, "Online adaptive equivalent consumption minimization strategy for fuel cell hybrid electric vehicle considering power sources degradation," Energy Conversion and Management, vol. 192, pp. 133-149, 2019.

[8] F. Martel, S. Kelouwani, Y. Dubé, and K. Agbossou, "Optimal economy-based battery degradation management dynamics for fuel-cell plug-in hybrid electric vehicles," Journal of Power Sources, vol. 274, pp. 367-381, 2015

[9] X. Hu, L. Johannesson, N. Murgovski, and B. Egardt, "Longevity-conscious dimensioning and power management of the hybrid energy storage system in a fuel cell hybrid electric bus," Applied Energy, vol. 137, pp. 913-924, 2015.

[10] T. Fletcher, R. H. Thring, M. Watkinson, and I. Staffell, "Comparison of Fuel Consumption and Fuel Cell Degradation Using an Optimised Controller," ECS Transactions, vol. 71, no. 1, pp. 85-97, 2016.

[11] T. Li, L. Huang, and H. Liu, "Energy management and economic analysis for a fuel cell supercapacitor excavator," Energy, vol. 172, pp. 840-851, 2019.

[12] M. Kandidayeni, A. Macias, A. A. Amamou, L. Boulon, S. Kelouwani, and H. Chaoui, "Overview and benchmark analysis of fuel cell parameters estimation for energy management purposes," Journal of Power Sources, vol. 380 , pp. 92-104, 2018.
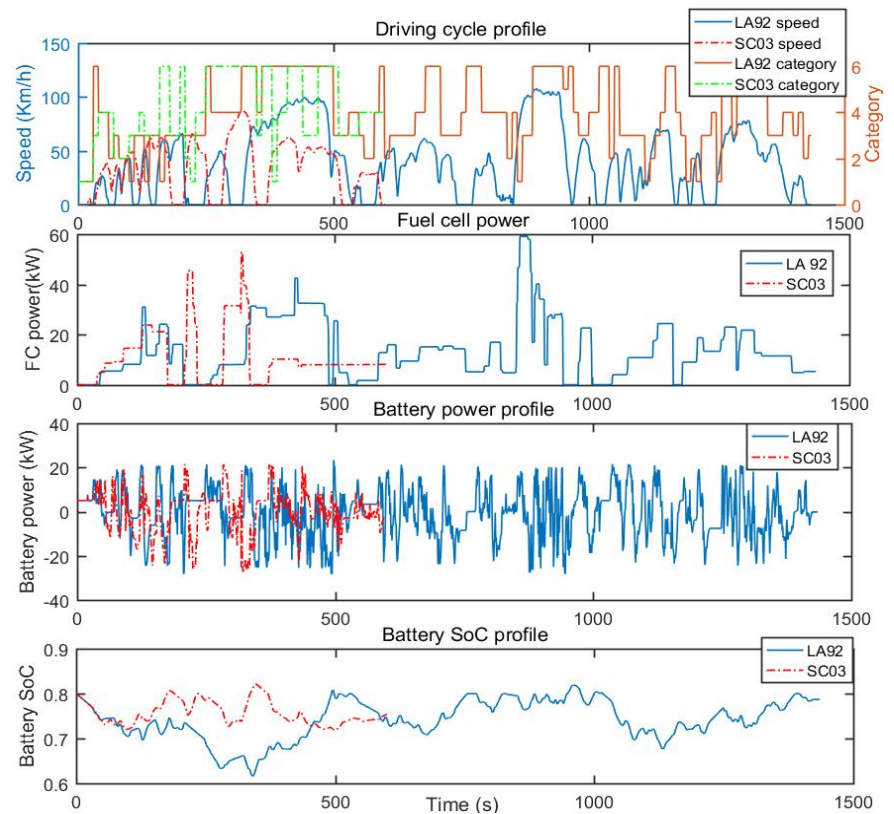

Fig. 17. Classifications and optimization results over LA92 and SC03 driving cycles

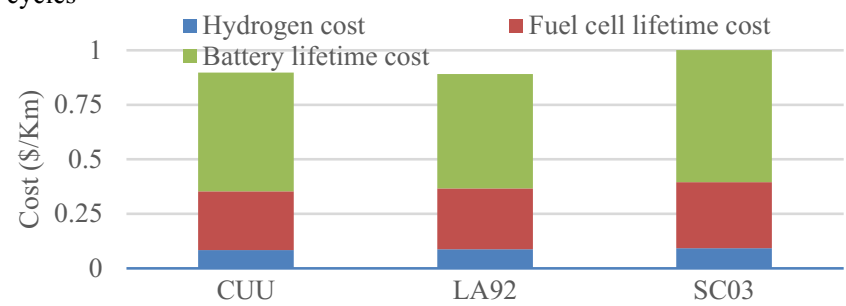

Fig. 18. Comparative results of optimal costs under three driving cycles

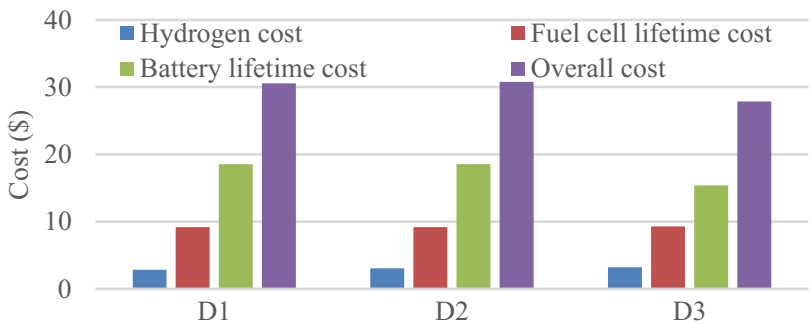

Fig. 19 Comparative optimization results under three degradation states

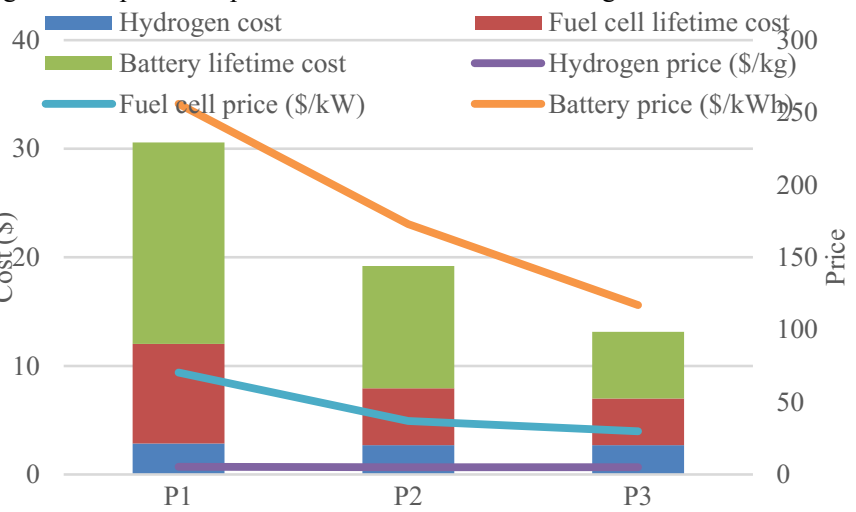

Fig. 20. Comparative results of optimal costs under three prices

[13] K. Ettihir, L. Boulon, and K. Agbossou, "Optimization-based energy management strategy for a fuel cell/battery hybrid power system," Applied Energy, vol. 163, pp. 142-153, 2016.

[14] M. Yue, S. Jemei, and N. Zerhouni, "Health-Conscious Energy Management for Fuel Cell Hybrid Electric Vehicles based on Prognostics-Enabled Decision-Making," IEEE Transactions on Vehicular Technology, pp. 11483-11491, 2019. 
[15] X. Hu, C. Zou, X. Tang, T. Liu, and L. Hu, "Cost-optimal energy management of hybrid electric vehicles using fuel cell/battery health-aware predictive control," IEEE Transactions on Power Electronics, pp. 1-1, 2019.

[16] F. Martel, Y. Dubé, S. Kelouwani, J. Jaguemont, and K. Agbossou, "Long-term assessment of economic plug-in hybrid electric vehicle battery lifetime degradation management through near optimal fuel cell load sharing," Journal of Power Sources, vol. 318, pp. 270-282, 2016.

[17] Y. Wang, S. J. Moura, S. G. Advani, and A. K. Prasad, "Power management system for a fuel cell/battery hybrid vehicle incorporating fuel cell and battery degradation," International Journal of Hydrogen Energy, vol. 44, no. 16, pp. 8479-8492, 2019.

[18] C. She, Z. Wang, F. Sun, and L. Zhang, "Battery aging assessment for real-world electric buses based on incremental capacity analysis and radial basis function neural network," IEEE Transactions on Industrial Informatics, pp. 1-1, 2019.

[19] L. Zhang, X. Ye, X. Xia, and F. Barzegar, "A real-time energy management and speed controller for an electric vehicle powered by a hybrid energy storage system," IEEE Transactions on Industrial Informatics, pp. 1-1, 2020.

[20] A. Tani, M. B. Camara, B. Dakyo, and Y. Azzouz, "DC/DC and DC/AC Converters Control for Hybrid Electric Vehicles Energy Management-Ultracapacitors and Fuel Cell," IEEE Transactions on Industrial Informatics, vol. 9, no. 2, pp. 686-696, 2013.

[21] P. Pei, Q. Chang, and T. Tang, "A quick evaluating method for automotive fuel cell lifetime," International Journal of Hydrogen Energy, vol. 33, no. 14, pp. 3829-3836, 2008.

[22] J. Purewal, J. Wang, J. Graetz, S. Soukiazian, H. Tataria, and M. W. Verbrugge, "Degradation of lithium ion batteries employing graphite negatives and nickel-cobalt-manganese oxide + spinel manganese oxide positives: Part 2, chemical-mechanical degradation model," Journal of Power Sources, vol. 272, pp. 1154-1161, 2014.

[23] P. Gazdzick, J. Mitzel, D. Garcia Sanchez, M. Schulze, and K. A. Friedrich, "Evaluation of reversible and irreversible degradation rates of polymer electrolyte membrane fuel cells tested in automotive conditions," Journal of Power Sources, vol. 327, no. Supplement C, pp. 86-95, 2016.

[24] M. Daigle and C. S. Kulkarni, "Electrochemistry-based battery modeling for prognostics," in in Annual Conference of the Prognostics and Health Management Society 2013, 2013.

[25] X. Lu and H. Wang, "Optimal Sizing and Energy Management for Cost-Effective PEV Hybrid Energy Storage Systems," IEEE Transactions on Industrial Informatics, pp. 1-1, 2019.

[26] D. Wang, J. Coignard, T. Zeng, C. Zhang, and S. Saxena, "Quantifying electric vehicle battery degradation from driving vs. vehicle-to-grid services," Journal of Power Sources, vol. 332, pp. 193-203, 2016.

[27] Q. Zhang, W. Deng, and G. Li, "Stochastic Control of Predictive Power Management for Battery/Supercapacitor Hybrid Energy Storage Systems of Electric Vehicles," IEEE Transactions on Industrial Informatics, vol. 14, no. 7, pp. 3023-3030, 2018

[28] C.-C. Chang and C.-J. Lin, "LIBSVM: A library for support vector machines," ACM Transactions on Intelligent Systems and Technology (TIST), vol. 2, no. 3, p. 27, 2011.

[29] E. Ruffini and M. Wei, "Future costs of fuel cell electric vehicles in California using a learning rate approach," Energy, vol. 150, pp. 329-341, 2018.

[30] G. Anandarajah, W. McDowall, and P. Ekins, "Decarbonising road transport with hydrogen and electricity: Long term global technology learning scenarios," International Journal of Hydrogen Energy, vol. 38, no. 8, pp. 3419-3432, 2013.

[31] J. Huya-Kouadio, "Doe hydrogen and fuel cells program record," 2017.

[32] M. Bressel, M. Hilairet, D. Hissel, and B. Ould Bouamama, "Remaining Useful Life Prediction and Uncertainty Quantification of Proton Exchange Membrane Fuel Cell Under Variable Load," IEEE Transactions on Industrial Electronics, vol. 63, no. 4, pp. 2569-2577, 2016.

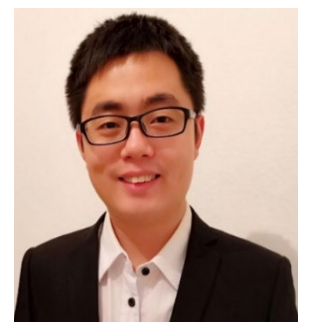

Huan Li (S'16-M'19)was born in Heze, China. He received the Master's degrees in vehicle engineering from Guizhou University, Guiyang, China, in 2015, and the Ph.D. degree in electrical engineering from the University of Technology of Belfort-Montbéliard (UTBM), Belfort, France, in 2018.
Currently, he is a Postdoctoral Researcher in the LUSAC laboratory, University of Caen Normandy, Saint-Lô, France. His main research interests include energy management for electric vehicles and microgrids, modeling and lifetime estimation of fuel cell and energy storage sources, and machine learning algorithms application into energy management.

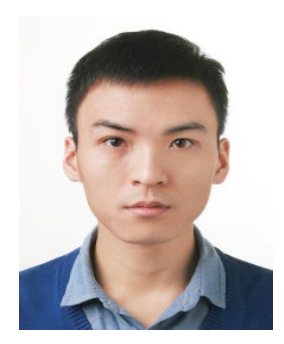

Yang Zhou (S'19) was born in Xi'an, China. He received the B.Eng. and M.S. degrees in electrical engineering from the Northwestern Polytechnical University, Xi'an, China, in 2014 and 2017, respectively. He is currently pursuing his Ph.D. degree at FEMTO-ST (UMR CNRS 6174), Department of Energy, and FCLAB (FR CNRS 3539), University of Bourgogne Franche-Comte, UTBM, Belfort, France. His main research interests include energy management strategy, fuel cell electric vehicle, model predictive control and driving prediction techniques.

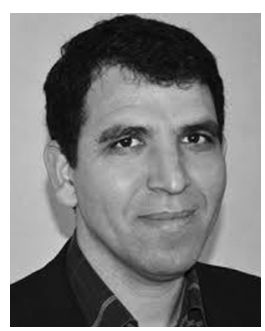

Hamid Gualous (M'14) was born in Morocco in 1967. He received the Ph.D. degree in electronics from the University Paris XI Orsay, Orsay, France, in 1994., From 1996 to 2009, he was an Associate Professor with the FEMTO-ST Laboratory, University of Franche-Comte, France. He is currently a Full Professor with the University of Caen-Basse Normandie, Caen, France, where he is also the Director of the LUSAC laboratory. His main research interests include energy storage device, marine renewable energies, and energy management systems for smart grids.

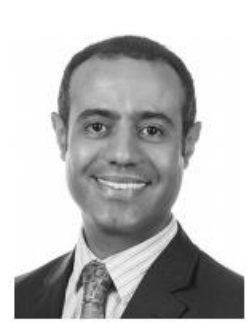

Hicham Chaoui (S'01-M'12-SM'13): received the Ph.D. degree in electrical engineering (with honors) from the University of Quebec, Trois-Rivières, QC, Canada, in 2012. From 2014 to 2016, he was an Assistant Professor at Tennessee Technological University, Cookeville, TN, USA. Since then, he has been a Faculty Member at Carleton University, Ottawa, ON, Canada. His research interests include adaptive and nonlinear control theory, intelligent control, robotics, electric motor drives, and energy conversion and storage systems.

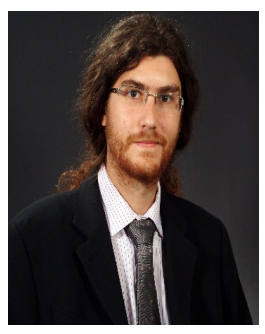

Loïc Boulon (M'10, SM'15) received the master degree in electrical and automatic control engineering from the University of Lille (France), in 2006. Then, he obtained a $\mathrm{PhD}$ in electrical engineering from University of Franche-Comté (France). Since 2010, he is a professor at UQTR and he works into the Hydrogen Research Institute (Full Professor since 2016). His work deals with modeling, control and energy management of multiphysics systems. His research interests include hybrid electric vehicles, energy and power sources (fuel cell systems, batteries and ultracapacitors). 